\title{
THE USE OF THE TAUTOPHONE ("VERBAL SUMMATOR") AS AN AUDITORY APPER- CEPTIVE TEST FOR THE STUDY OF PERSONALITY*
}

\author{
DAVID SHAKOW \\ AND \\ SAUL ROSENZWEIG \\ Worcester State Hospital, Worcester, Massachusetts
}

In recent years apperceptive measures of personality have played an increasingly greater part in clinical and experimental psychology. Among such devices none has proved more successful or been more widely adopted than the Rorschach Test. This consists of a series of ten cards on each of which a symmetrical ink blot-sometimes in color, sometimes just black and white-appears. These cards are offered to the subject individually with the instructions that he is to say what the blot reminds him of, what it might represent. Whatever the associations produced, they are written down by the examiner and scored primarily as to certain formal characteristics-the sharpness of form perception, the prevalence of color or movement responses-and secondarily as to content. The psychograph resulting from the totals and relationships appearing in these scores has been shown repeatedly to be of great psychological significance for the revelation of both normal and abnormal personality characteristics. This fortunate outcome is not so surprising if it is recalled that this test-unlike many other personality tests-is a sampler of real behavior and is, moreover, scored in a way which the subject can usually not fathom in advance.

The Rorschach Test employs one sensory or perceptual modality - the visual-and it is therefore natural that the impetus to exploit others, particularly the auditory, should arise. The frequent occurrence in daily life of "mishearing" with self-reference and the

* Substantially as presented at the Columbus meeting of the American Psychological Association, Sept., 1938. (Cf. Psychol. Bull., 1938, 35, 647.) 
marked prevalence of auditory hallucinations in psychotics bespeaks the probable fruitfulness of such an approach.

Now it would appear that a device originated by B. F. Skinner ${ }^{1}$ for the purpose of testing certain hypotheses with regard to the development of speech might be adapted as an auditory apperceptive test. The apparatus in question repeats patterns of vowels recorded on phonograph discs. It consists of a phonograph, an attachment which automatically resets the pickup so that any particular section of the record may be repeated as many times as wished, and discs on which are recorded series of vowel-combinations occurring at regular intervals. Samples of single patterns are: $\mathfrak{u}$ ' 'e (ס̄oh, ŭh,

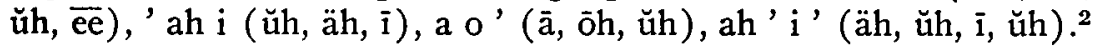

Skinner called the instrument a "verbal summator," but since we were not particularly concerned with nor able to accept certain of the theoretical implications of this name, it seemed advisable to substitute a more purely descriptive one. The designation adopted was "tautophone."

In the present paper we shall describe the technique of administering the test, methods of scoring it, and some of its possibilities for personality diagnosis. In a later publication results from a group of normal and schizophrenic subjects will be presented.

\section{Method of Presentation}

In our experiment the subject was shown the apparatus and told: "Here is a phonograph. On it is a record with a man's voice saying different things. He speaks rather unclearly so I'll play over what he says a number of times. You'll have to listen carefully. As soon as you have some idea of what he's saying tell me at once."3 The subject was then directed to another part of the room where he was requested to make himself comfortable on a couch about eight feet from the phonograph. The latter was concealed behind a screen. One of the experimenters ran the apparatus and kept a record of the number of stimulus repetitions preceding a response. The other experimenter, in the same part of the room as the subject, recorded the responses and any other pertinent information, and notified the experimenter running the apparatus when the subject was ready for

${ }^{1}$ Skinner, B. F. The verbal summator and a method for the study of latent speech. J. Psychol., 1936, 2, 71-107.

${ }^{2}$ For the principles on which the patterns were constructed and for other technical details reference should be made to Skinner's article.

${ }^{s}$ It will be noticed that our instructions are different from those of Skinner. We deemed it advisable to make the instructions as simple as possible since we were interested in applying the test particularly to psychotic subjects. 
the next stimulus pattern. There was a lapse of about thirty seconds between successive stimuli. The whole experiment lasted from twenty to thirty minutes on the average. ${ }^{4}$ Twenty auditory patterns, taken from one of the original records supplied by Skinner, were used as stimuli.

\section{Scoring System: Item Responses}

The scoring system adopted considers both the formal nature of the responses and their content. Table 1 presents the classificatory system adopted for the formal aspects. Here responses are scored according to complexity of structure, similarity to stimulus pattern, English or non-English nature, personal reference and sentence structure. The definitions for the various categories under each of these headings require discussion.

Complexity of Structure. Under this rubric come five categories: syllables, nonmeaningful words, meaningful words, phrases and sentences. By a syllable $(S Y)^{5}$ is meant an elemental sound or combination of such sounds, each of which is uttered with a single effort or impulse. A nonmeaningful word $(W N)$ is defined as a combination of syllables constituting a word which is not recognizable as having meaning in any accepted language known to the examiner and which the subject cannot convincingly demonstrate to be a word. A response of more than one such word also falls into this category. A meaningful word (WM) is a discrete word having meaning in some accepted language. A response of several disconnected words also falls into this category. A phrase $(P)$ is a series of connected meaningful words lacking either a subject or a predicate and used as a single expression. A sentence $(S)$ is a series of connected words with both subject and predicate (explicit or understood) expressing a complete thought.

Similarity to Sample. This classification considers how closely the response resembles the stimulus pattern. Two categories are recognized: close and remote. Close $(c)$ responses are those in which at least half of the content of the stimulus is approximated. Remote $(r)$ responses are those in which resemblance to less than half of the original occurs.

Non-English. Three categories come under this heading: foreign, doubtful foreign with no meaning assigned, doubtful

'It is possible for one individual to perform all these tasks after a little practice. It seems advisable, however, to keep the apparatus screened from the subject in order to avoid distractions and to insure realistic conditions for response.

$\checkmark$ Each of the categories has a symbol assigned to it for purposes of economy in reference. 
TABLE 1

Classification System for Items (Tautophone)

\begin{tabular}{|c|c|c|c|c|c|c|}
\hline & $\begin{array}{c}\text { COMPLEXITY } \\
\text { OF } \\
\text { STRUCTURE }\end{array}$ & $\begin{array}{l}\text { SIMILARITY } \\
\text { TO SAMPLE }\end{array}$ & $\begin{array}{c}\text { Non-English } \\
\text { RESPONSE }\end{array}$ & $\begin{array}{c}\text { Personal } \\
\text { Rererence }\end{array}$ & $\begin{array}{l}\text { SENTENCE } \\
\text { StrRUCTURE }\end{array}$ & $\begin{array}{l}\text { SAMPLE } \\
\text { SYMBOLS }\end{array}$ \\
\hline & \multirow{2}{*}{$\begin{array}{l}\text { Syllable (s) } \\
\text { (SY) }\end{array}$} & Close (c) & & & & SYc \\
\hline$p$ & & Remote (r) & & & & $S Y_{r}$ \\
\hline$\frac{\pi}{4}$ & \multirow{2}{*}{$\begin{array}{r}\text { Word (s) } \\
\text { (WN) }\end{array}$} & Close (c) & $\begin{array}{l}\text { Probable non-English (?) } \\
\text { Assigns Meaning (X) }\end{array}$ & & & WNe? \\
\hline z & & Remote (r) & $\begin{array}{l}\text { Probable non-English (?) } \\
\text { Assigns Meaning (X) }\end{array}$ & & & WNrX \\
\hline & \multirow{2}{*}{$\begin{array}{l}\text { Word (s) } \\
(W M)\end{array}$} & Close (c) & $\begin{array}{l}\text { Non-English (-) } \\
\text { Probable non-English (?) }\end{array}$ & $\begin{array}{l}\text { First Person (1) } \\
\text { Second Person (2) } \\
\text { Third Person (3) } \\
\text { Impersonal (4) }\end{array}$ & & $\begin{array}{l}\text { WMc2 } \\
\text { WMc-3 }\end{array}$ \\
\hline & & Remote (r) & $\begin{array}{l}\text { Non-English (-) } \\
\text { Probable non-English (?) }\end{array}$ & $\begin{array}{l}\text { First Person (1) } \\
\text { Second Person (2) } \\
\text { Third Person (3) } \\
\text { Impersonal (4) }\end{array}$ & . & $\begin{array}{l}\text { WMr1 } \\
\text { WMr?4 }\end{array}$ \\
\hline \multirow{4}{*}{ 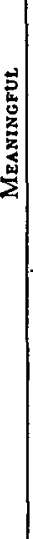 } & \multirow{2}{*}{$\begin{array}{l}\text { Phrase (s) } \\
\text { (P) }\end{array}$} & Close (c) & $\begin{array}{l}\text { Non-English (-) } \\
\text { Probable non-English (?) }\end{array}$ & $\begin{array}{l}\text { Firat Person (1) } \\
\text { Second Person (2) } \\
\text { Third Person (3) } \\
\text { Impersonal (4) }\end{array}$ & & $\begin{array}{l}\text { Pc2 } \\
\text { Pc?4 }\end{array}$ \\
\hline & & Remote ( $r$ ) & $\begin{array}{l}\text { Non-English ( }(-) \\
\text { Probable non-English (?) }\end{array}$ & $\begin{array}{l}\text { First Person (1) } \\
\text { Second Person (2) } \\
\text { Third Person (3) } \\
\text { Impersonal (4) }\end{array}$ & & $\begin{array}{l}\mathrm{Pr}-3 \\
\mathrm{Pr} 4\end{array}$ \\
\hline & \multirow{2}{*}{$\begin{array}{l}\text { Sentence (s) } \\
\text { (S) }\end{array}$} & Close (c) & $\begin{array}{l}\text { Non-English (-) } \\
\text { Probable non-English (?) }\end{array}$ & $\begin{array}{l}\text { First Person (1) } \\
\text { Second Person (2) } \\
\text { Third Person (3) } \\
\text { Impersonal (4) }\end{array}$ & $\begin{array}{l}\text { Declarative (l.]) } \\
\text { Interrogative ([?]) } \\
\text { Imperative ([!]) }\end{array}$ & $\begin{array}{l}S c[.] 1 \\
\operatorname{Sc}[?] 2 \\
S c-[!] 3\end{array}$ \\
\hline & & Remote (r) & $\begin{array}{l}\text { Non-English (-) } \\
\text { Probable non-English (?) }\end{array}$ & $\begin{array}{l}\text { First Person (1) } \\
\text { Second Person (2) } \\
\text { Third Person (3) } \\
\text { Impersonal (4) }\end{array}$ & $\begin{array}{l}\text { Declarative ([.]) } \\
\text { Interrogative ([?]) } \\
\text { Imperative ([!]) }\end{array}$ & $\begin{array}{l}\text { Sr? [.] } 1 \\
\text { Sr [?] } 2 \\
\text { Sr- [!] } 4\end{array}$ \\
\hline
\end{tabular}

foreign with meaning assigned. By foreign (-) is meant a response the greater part of which is of a recognized foreign language. By doubtful foreign, meaning unassigned (?) is meant a response the greater part of which is held by the subject to be foreign but which is not recognized by the examiner plausibly to be such. These responses are frequently neologisms. By doubtful foreign, meaning assigned $(? X)$ is meant a response, the greater part of which consists of meaningless words to which the subject assigns meaning. Personal Reference. This classification is concerned with the 
kind of personal reference contained in the response and subsumes four categories : first person, second person, third person, and impersonal. Under first person (1) are included those responses where a first person pronoun or the subject's own name occurs. Under second person (2) come those responses where a second person pronoun or a proper name in direct speech is used. Third person (3) includes those responses which involve a third person pronoun, definite or indefinite, or a proper name. In the category impersonal (4) are included responses where the reference is not to humans.

Sentence Structure. This classification is concerned with the distinction between types of sentences : declarative, interrogative, and imperative. The distinctions here are grammatical, the declarative ([.]) being a sentence that ends with a period, the interrogative ([?]) one that ends with a question mark, and the imperative ([!]), either exclamatory or injunctive, one which ends with an exclamation point.

At this juncture it may be helpful to give a few examples from actual protocols in order to clarify the scoring system:

Stimulus pattern

'u'i'*
u'a
'ao
"eu
'ah'i
i"'u
'iu'

Response

ooh, uh, r

$\bar{o}, \mathbf{r}$

Tahão (name of an Indian village)

A hoodoo

about a pint

I was born on a square piece of land.

Goodbye, Hoover!
Score

SYc

SYr

WNe?x

W Mc3

$\mathrm{Pc} 4$

$\operatorname{Sr}[]$.

$\operatorname{Sc}[i] 2$

*All sounds are long sounds except ah (a as in far) and "" (apostrophe) which is the symbol for $\breve{u}$ ( $\breve{u}$ as in mud).

Another factor considered is the number of repetitions-the number of repetitions of a stimulus pattern necessary for eliciting a response.

Rules for the application of these individual response scoring categories were found necessary to insure consistency, and the following were adopted.

General Principles: When a choice is possible, scoring is always to be in terms of what might be considered a "higher" level of response, e.g., meaning rather than nonmeaning, sentence rather than phrase, close rather than remote. In other cases the selection is arbitrary, e.g., first rather than second person, declarative rather than interrogative (interrogative rather than imperative), English rather than non-English, etc. The order of preference is the order as given in Table 1 . 
Meaningfulness: (1) If there is any meaning in the word or words, the response should be included under the meaningful category. (2) Only words and syllables may be nonmeaningful. Sounds indicated as coming from animals are credited as meaningful (e.g., bow-wow).

Complexity of Structure: Where more than a phrase is indicated by the structure or by the intonation, a sentence should be credited. (Sample: Oh, later!)

Each response is further classified for predominant content. The pertinent Rorschach categories may here be employed.

\section{Scoring System: Totality of Responses}

Thus far the scoring system for the responses to the separate items has been considered. Various methods of analysis were also elaborated to deal with the responses considered collectively. These consisted of the following:

1. Totals. The number of responses falling into each of the categories of complexity, similarity, non-English, personal reference and sentence structure; the mean and range of the repetitions.

2. Indices. Various measures of relationship among the just mentioned categories. Although a considerably larger number of indices have been examined, some of which appear to have promise, we shall limit ourselves here to the indices which thus far seem the most valuable. In order to have comparable ranges in the several indices, the generalized formula $\frac{x-y}{x+y}$ was adopted. ${ }^{6}$ This gives a limited but sufficiently wide range, +1.0 to -1.0 , and a readily interpretable index since one can tell at a glance in which direction the specific score falls. (Zero incidence in both numerator and denominator is arbitrarily given a zero value.) The indices with their respective formulas are given in Table 2.

For the present these indices must be considered as deriving largely from logical and a priori psychological considerations although they are also based on empirically determined data. They appear to have promise for personality diagnosis but their tentative nature must be strongly emphasized. The next important step is the validation of these indices against diagnostic personality data of other types.

The first index is one we have termed "suggestibility." It expresses the relationship between $\mathrm{S}+\mathrm{P}$ to $\mathrm{SY}$. This ratio has

${ }^{\circ}$ We are grateful to $\mathrm{E}$. M. Jellinek for the suggestion. 
been considered an index of suggestibility because it measures in some degree the acceptance of the instructions which call for the interpretation of the vowel pattern as "a man saying something." Acceptance of this suggestion would result in the production of a sentence or a phrase. Extreme lack of acceptance of the suggestion

TABLE 2

INDICES FOR TAUTOPHONE

\begin{tabular}{l|l}
\hline \multicolumn{1}{c|}{ Index } & \multicolumn{1}{c}{ Formula } \\
\hline 1. Suggestibility & $\frac{(\mathrm{S}+\mathrm{P})-\mathrm{SY}}{(\mathrm{S}+\mathrm{P})+\mathrm{SY}}$ \\
\hline 2. Contact & $\frac{(\mathrm{SYc}+\mathrm{WNc})-(\mathrm{SYr}+\mathrm{WNr})}{(\mathrm{SYc}+\mathrm{WNc})+(\mathrm{SYr}+\mathrm{WNr})}$ \\
\hline 3. Human Reference & $\frac{(1+2+3)-4}{(1+2+3)+4}$ \\
\hline 4. Self-Reference & $\frac{1-(2+3)}{1+(2+3)}$ \\
\hline 5. Subjectivity & $\frac{(\mathrm{Pr}+\mathrm{Sr})-(\mathrm{Pc}+\mathrm{Sc})}{(\mathrm{Pr}+\mathrm{Sr})+(\mathrm{Pc}+\mathrm{Sc})}$ \\
\hline 6. Interrogativeness & $\frac{[?]-\mathrm{S}}{[?]+\mathrm{S}}$ \\
\hline
\end{tabular}

would result in the mere reproduction of the stimulus pattern, i.e., syllables. The relationship between the two types of response should give a measure of the degree to which the suggestion is acceptedfor the present purposes, suggestibility.

The second index-"contact"-is obtained by relating the scores on the $c$ and $r$ responses falling in the SY and WN categories. The rationale for this is that if the subject gives $S Y$ and $W N$ responses, i.e., responses which are virtually repetitions of the stimulus pattern, albeit of greater or lesser complexity, and if these responses are not accurate repetitions of the stimulus, then this reflects a lack of contact with the environment represented by the experimental situation (The presence of hearing difficulty must of course be determined and guarded against.)

The index "human reference" is constructed by relating the 
responses involving inanimate or nonhuman material (4) to the human references $(1+2+3)$.

The index "self-reference" is obtained by relating the responses with first person references (1) to the sum of the second person (2) and third person (3) responses. The basis for this index is obvious.

The next index-"subjectivity"-relates the remote and close $\mathrm{P}$ and $\mathrm{S}$ responses. The argument for its construction is as follows: In giving responses which have content of a meaningful kind (especially $\mathrm{P}$ and $\mathrm{S}$ ), such content may be affected to a greater or lesser degree by the personal problems of the subject. If personal problems or autistic preoccupations influence the response, the chances of its falling into the $r$ category are considerably increased; whereas if the subject keeps his response close to the stimulus pattern the chances are much decreased. There is doubt with regard to this index because it involves, to some extent, factors which play a part in the "contact" index (the $r$ and $c$ aspects of the responses). However, we believe that the $r-c$ factor plays a much less important role in the present context than it does in the case of nonmeaningful responses, where it could signify little else than lack of contact. A scatter diagram of these two indices based on data from forty subjects shows only a minor relationship.

The last index to be presented is called "interrogativeness" and is based on the relation between the sentences in interrogative form and the total number of sentences. It is thus an attempt to distinguish between subjects who make assertions, whether declarative or imperative in form, and those who ask questions.

Besides the totals and indices just mentioned, there are two other types of analysis which are made of the whole examination:

3. Sequence. Shifts during the course of the examination in the order of various types of complexity, closeness, or other characteristics.

4. Content. Predominant kinds of content represented in the responses.

Two sample records, Tables 3 and 4 , one of a normal subject and the other of a hebephrenic schizophrenia patient, are here given to convey a clearer impression of the test and the scoring as a whole. The normal subject was an attendant of twenty-five, an affable, dapper Frenchman of some ability but rather irresponsible. The patient was a thirty-seven year old hebephrenic who had been in the hospital for seventeen years. According to his story he had "come 
to the hospital instead of going to Harvard." At the time of the examination he was quite silly and showed some disintegration of thought and affect. He was making a fair institutional adjustment, working on an outside gang and on the wards. Among his symptoms was one which indicated a marked confusion between symbol and referent, viz., he would write "juicy steak" or similar items on pieces of paper and then swallow the paper.

\section{Comparison of Sessions}

In those instances where the experiment is repeated an analysis of consistency between sessions is made under three categories: identical, similar, dissimilar. Identical ([1]) are those responses which are the same as the corresponding ones of the first session. Similar ([2]) are those responses which are identical in at least half of their content but are not entirely so. Dissimilar ([3]) are those responses which are the same as the corresponding ones of the first session in less than half of their content.

\section{Comparison with Rorschach Test}

It will have been noticed by those who are acquainted with the Rorschach Test that there are similarities between some of its analytic categories and those employed here. Although we are not particularly concerned to emphasize this similarity or to argue in any way that our measures have the same or even similar meanings to those of the Rorschach, it may be of interest in passing to point out some of the more obvious likenesses.

\section{TABLE 3}

TAUTOPHONE RECORD FORM

Name $A . B$. Age 31 Diagnosis Normal Hearing $N o$ defect Languages other than English none

Date Oct. 22, 1937 Length of Session $25 \mathrm{~min}$.

\begin{tabular}{|c|c|}
\hline Stimulus & Response \\
\hline 1. i"a' & I am a very \\
\hline $\begin{array}{l}\text { 2. Aho"' } \\
\text { 3. u"e }\end{array}$ & $\begin{array}{l}\text { I know I'm not } \\
\text { Who are thee? }\end{array}$ \\
\hline & $\begin{array}{l}\text { Higher fire } \\
\text {. }\end{array}$ \\
\hline $\begin{array}{l}\text { 5. "e ah" } \\
6 . " \mathrm{eu}\end{array}$ & $\begin{array}{l}\text { Twenty } \mathrm{r} f \\
\mathrm{rg} \text { two }\end{array}$ \\
\hline $\begin{array}{l}\text { 7. 'ai } \\
\text { 8. 'e"ah }\end{array}$ & My knees are \\
\hline $\begin{array}{l}\text { 9. 'ah i } \\
\text { 10. 'u"o }\end{array}$ & üh ri \\
\hline 12. 0 & Even in the face \\
\hline & ō a double-u \\
\hline & Not half a pie \\
\hline
\end{tabular}

No. Repet. Score

Remarks

$16 \mathrm{Sr}[]$.

17 Sc[.]1

15 Sc[?]2

18 Pc 4

8 SY c

20 SYc

9 SY c

15 Sc[.]1

11 SY c

11 SY c

10 Pc 4

12 SY $\mathrm{c}$

14 Pc 1

$37 \quad \mathrm{Pc} 4$ 

15. 'u ah"
16. 'a o
17. u'a
18. 'u'i'
19. "ah o'
20. i" $u$ '
Blue harvester
Bass hoe
Blue Café
Blue cafire
ŭh $\mathrm{rō} f$
I own a blue car

$\begin{array}{lrl} & 9 & \text { Pc4 } \\ & 30 & \text { WMc4 } \\ & 6 & \text { Pc4 } \\ \text { Never heard word "cafire" } & 26 & \text { WMc4 } \\ & 10 & \text { SYc } \\ & 9 & \text { Sc[.]1 } \\ & & \\ & & \\ \text { Mean } & 15.2 & \\ \text { Range } & 6-37 & \end{array}$

Tabulation

$\begin{array}{ll}\text { SYr } & 0 \\ \text { SYc } & 7\end{array}$

WNr 0

WNe 0

Non-English-none

Category :

Number:

Indices:

Suggestibility $\ldots \ldots \ldots \ldots \ldots, \quad .22$

Contact $\ldots \ldots \ldots \ldots \ldots \ldots \ldots, 1.00$

Human Reference ........... - 08 $\begin{array}{llllll}\text { WMr } & 0 & \text { Pr } & 0 & \text { Sr } & 1 \\ \text { WMc } & 2 & \text { Pc } & 6 & \text { Sc } & 4\end{array}$

$\begin{array}{ccccc}{[1]} & 1 & 2 & 3 & 4 \\ 0 & 5 & 1 & 0 & 7\end{array}$

Subjectivity ............. -82

Interrogativeness $\ldots \ldots \ldots \ldots \ldots-.67$
Self-Reference $\ldots \ldots \ldots \ldots \ldots .67$

TABLE 4

Tautophone Record Form

Name C.D. Age 35 Diagnosis Schizophrenia-Heb. Date June 26, 1936 Hearing No Defect Languages other than English none Length of Session 35 min.

\begin{tabular}{ll} 
Stimulus & \multicolumn{1}{c}{ Response } \\
1. i"a' & He is a bigger \\
2. ah o"" & I fo-fo-ko \\
3. u"e & Where are we? \\
4. i'i' & Ova fiva \\
5. 'e ah" & Radda \\
6. "eu & Hindu
\end{tabular}

7. 'a i

8. 'e"ah

9. 'ah i

10. 'u'o

11. e"'a

12. $0 \mathrm{a} "$

13. 'iu'

14. 'ah'i

15. 'wah"

16. 'a 0

17. u'a

18. 'u'i'

19. "ah o'

20. i"u'
A fãgă

Weaker any part

Our part

John Doe

Keep out of

the room

Johnny Cooper

Not far?

Put a piece of pie Adds "in a bag"

Dāgo

Ru-ku-go

Go to a rock

higher than I!

Oh bell

I ain't got no food.

\section{Remarks}

"Anybody who does what he wants to do."

"A Papa"

No.

Repet. Score

$7 \mathrm{Sr}[]$.

$15 \mathrm{SYr}$

5 Scl?]1

10 SYc

30 SY

5 WMc3

13 WNc?X

23 Pc 4

18 Pc 1

13 Pc 3

(60)

50. SrI!!]2

$40 \quad \mathrm{Pc} 3$

25 Sr[?]4

$12 \operatorname{Sr}[!] 2$

6 WMc3

7 SYr

10 Sc[!]1

"Get the milk and eat the grass." $10 \quad \operatorname{Pr} 4$

\section{Tabulation}

$\begin{array}{ll}\text { SYr } & 3 \\ \text { SYc } & 1 \\ \mathrm{X} & 1\end{array}$

Category:

Number:

Indices:

Suggestibility $\ldots \ldots \ldots \ldots \ldots, \quad .50$

Contact $\ldots \ldots \ldots \ldots \ldots \ldots, \ldots,-.20$

Human Reference

$\begin{array}{llll}\text { WNr } & 0 & \text { WMr } & 0 \\ \text { WNc } & 1 & \text { WMc } & 2\end{array}$

$\begin{array}{cc}{[.]} & {[?]} \\ 2 & 2\end{array}$

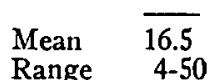

$\begin{array}{ll}\text { Range } & 4-50\end{array}$

Sr 4

Sc 3

$\begin{array}{ccccc}{[!]} & 1 & 2 & 3 & 4 \\ 3 & 4 & 2 & 5 & 3\end{array}$

Self-Reference .......... -27

Subjectivity .................. $=.17$

Interrogativeness $\ldots \ldots \ldots \ldots \ldots-.56$ 
With regard to mode of apperception, the analogy to the wholepart analysis of the Rorschach is found in the present complexity of structure (sentence element) analysis. The Erfassungstypus (G-D relation) determination is perhaps similar in some degree to such indices as suggestibility in which the relationship between elements (SY) and wholes (P,S) is considered. The Sukzessionstypus is, possible in the tautophone material, too, as witness the sequence analysis described above.

With respect to qualitative aspects, various analogies may be drawn between the tautophone's English/non-English, sentence structure, etc., categories with the form, movement and color categories of the Rorschach. "Goodness" or "badness" of perception $(\mathrm{F}+$ and $\mathrm{F}-)$ are analogous to the $r$ and $c$ categories, and the Rorschach $F+$ percentage is similar to the contact index in that the latter, too, is concerned with "goodness" of form. Indices such as subjectivity and self-reference may after further study be found to be related to introversiveness and extratensiveness or Erlebnistypus (B : $\Sigma \mathrm{Fb}$ ).

From the standpoint of content, originality, commonness of response, etc., may, as in the Rorschach, also be determined in the present examination when sufficient data for criteria accumulate.

Reaction time for the first response on each Rorschach card, as used for the determination of color shock, may be considered as having a similar meaning to the tautophone scores on number of stimulus repetitions preceding each response and the range of these scores.

\section{SUMMARY}

An auditory apperceptive test employing the tautophone (verbal summator) as apparatus is described. Tentative scoring and interpretative systems are presented with illustrations. A discussion of certain similarities between the Rorschach and the present test is given. In a second article the application of this method to a group of schizophrenic and normal adults will be reported. 